\title{
Las formas simples del romancero hispánico*
}

\author{
The simple forms of Hispanic romancero
}

Luis Beltrán Almería

Universidad de Zaragoza

RESUMEN: André Jolles propuso hace más de ochenta años un sistema de formas simples (einfache Formen) que estaría en el origen de los géneros culturales. A partir de estas formas simples este artículo propone una aproximación al romancero hispánico renovada. Se trata de encontrar las formas simples del romancero y superar su clasificación por temas y origen. Tales formas simples serían el caso, la historia personal, la anécdota, la lamentación, la consolación, el sueño y el milagro, la burla y la protonovela.

Palabras clave: formas simples, Jolles, romancero, balada, tradición, épico-lírica.

ABSTRACT: André Jolles proposed more than eighty years ago a system of simple forms (einfache Formen) that would be at the origin of the cultural genres. This paper proposes a renewed approach to Hispanic romancero from these simple forms. It's about finding the simple forms of romancero and overcome its subject and origin classification. These simple shapes would be the case, personal history, anecdote, lamentation, consolation, dream and miracle, mockery and protonovel.

Keywords: Simple forms, Jolles, romancero, ballad, tradition, epic-lyric.

Suele decirse de nuestro romancero viejo que es comparable a la epopeya homérica en grandeza literaria. En efecto, la colección de romances antiguos conservada es una de las grandes bazas del patrimonio cultural hispánico si no es la más grande. Y algo similar puede decirse del minusvalorado romancero vulgar y nuevo. Sin embargo, la escuela de filología española ha ofrecido mag-

\footnotetext{
* Este artículo forma parte del proyecto de investigación GENUS, MINECO FFI2013-40833-P.
} 
níficos estudios sobre el género, pero viene sufriendo un cierto estancamiento en las últimas décadas. En España, la tradición moderna ha perdido visibilidad, dada la erosión que la cultura moderna ha causado en la cultura oral tradicional, aunque, desde hace dos décadas, se viene abriendo paso una línea de investigación sobre otras formas de poesía oral que habían quedado desatendidas por los estudiosos de la oralidad. No ocurre así en otros países hispanos. En México, como es bien sabido, la tradición del romance-balada está bien viva y ha dado lugar a una hermosa colección de corridos sobre la revolución e, incluso, a géneros nuevos como el de los narcocorridos.

Además de la aproximación española, encabezada por Menéndez Pidal y su escuela, ha habido otras aproximaciones dignas de tenerse en cuenta. La estilística alemana supo ver el simbolismo del romancero (en especial, Leo Spitzer, un trabajo que retomó Julio Rodríguez Puértolas, 1976). En la segunda mitad del siglo XX han florecido los estudios sobre la oralidad, sin que este hecho haya tenido repercusiones en los estudios del romancero. Vamos a dedicar este escrito a mostrar una posibilidad de aproximación al romancero a partir de un trabajo aparecido en 1930 del estudioso alemán André Jolles. Aunque nos interesa especialmente el romancero viejo, esta posibilidad no se limita a la forma medieval-renacentista del romance sino que está abierta a las formas del romancero nuevo y a su pervivencia ${ }^{1}$.

El romancero hispánico viene siendo considerado un género de la tradición, gracias sobre todo a los esfuerzos de R. Menéndez Pidal. En efecto, es un género y es una parte de la tradición. Pero vamos a considerar aquí esa categoría a la luz de un planteamiento a la vez viejo y nuevo. Ese planteamiento se puede resumir del siguiente modo. El romancero se sitúa en una zona fronteriza entre la oralidad (de la que surge) y la escritura, en la que tiene una continuidad como romancero vulgar y moderno (Martínez Torner, 1966). Desde hace tiempo se ha señalado que los temas y materiales (motivos dirían los folcloristas) del romancero son también patrimonio de otros géneros de la tradición (la lírica popular, la canción tradicional, el cuento, el teatro popular, etc.). La novedad que intentamos formular ahora viene a proponer que distingamos entre el género cultural y el género de la enunciación o formas simples, retomando la

\footnotetext{
${ }^{1}$ Por esta razón he elegido para dar referencia de los romances la edición de Mariano de la Campa Gutiérrez (Antología de la épica y el romancero). Esta antología ofrece testimonios vinculados entre la tradición antigua y la tradición oral moderna, algo que nos será de gran utilidad en esta aproximación. Para romances vulgares y nuevos remito a la edición de Flor Salazar (1999). Doy referencias parentéticas a las respectivas versiones de romances. Los paréntesis formados por un número romano (V para los romances de la tradición antigua y VI para los de la tradición moderna) y un número arábigo se refieren a la versión correspondiente de la antología de Mariano de la Campa. Los paréntesis que contienen una "S" se refieren a la obra de Flor Salazar. Las referencias son siempre a romances, no a páginas.
} 
terminología que empleara Jolles hace más de ochenta años. Jolles concibió la idea de identificar y determinar las formas del discurso (Gestalt) que subyacen en la literatura. Estas formas compondrían un sistema de nueve elementos simples: Légende, Sage, Mythe, Rätsel, Spruch, Kasus, Memorabile, Märchen y Witz (leyenda, gesta, mito, adivinanza, locución, caso, recuerdo, cuento y facecia). En cada forma Jolles intenta mostrar las correspondencias entre ejemplos europeos, hindúes y semitas, y caracterizar la disposición mental que la funda. Siguiendo el ejemplo de Jolles (debidamente actualizado y revisado con los progresos de la teoría de la enunciación y la literatura comparada), observamos que el romancero medieval o nuevo, de tradición antigua o moderna, acoge formas simples y formas complejas y que tanto unas como otras pueden aparecer en otros géneros culturales de transición entre la oralidad y la escritura. Las formas simples (o géneros de la enunciación) que hemos constatado son: el caso, la historia personal, la lamentación, la broma o engaño, la anécdota histórica, la consolación, el testamento (consejos de un moribundo), el misterio-sueño y la leyenda. Las formas complejas, en especial la protonovela, son el producto de la acumulación de formas simples ${ }^{2}$. Este asunto de las formas simples tiene una trascendencia que voy a tratar de explicar en pocas palabras. El concepto de formas simples tiene una naturaleza empírica. Jolles vio que esos géneros tenían un lugar relevante en la historia de la cultura y, en concreto, en la dinámica de los géneros del discurso y se propuso un acercamiento comparado. Desde la filología española este planteamiento no ha recibido interés porque ha parecido suficiente un planteamiento histórico-temático: los romances se clasifican por su origen y por sus temas: históricos, épico-literarios y novelesco-aventureros (con variantes) ${ }^{3}$. El criterio histórico debería ser un criterio suficiente, pero, como es obvio, tropezamos con los problemas de datación de unos géneros populares, de naturaleza oral, de los que no tenemos certezas en su etapa primera. Más allá de la primera etapa — la de los siglos XIII al XV— no queda otro criterio que el temático. Este es un planteamiento que es preciso superar a la vista de los avances teóricos de los que hoy disponemos. En otras palabras: conviene ver en los romances — viejos o nuevos— algo más que temas. Ese algo más deben ser géneros, pero no cualquier tipo de géneros sino aquellos que tienen un papel esencial en la transición de las culturas tradicionales (las de la oralidad) a las culturas históricas (las de la escritura). Y es a este respecto

\footnotetext{
${ }^{2}$ Esta enumeración de formas simples puede estar afectada por la selección que, desde el siglo XVI, han venido haciendo los compiladores. Este hecho fue apuntado por Menéndez Pidal (1953: 9) y él mismo confiesa no atender a los romances puramente líricos o descriptivos.

${ }^{3}$ El hispanista inglés William J. Entwistle (1969: 57-60) estudió la balada europea y propuso una tipología mixta, que combina temas con orígenes. Ve Entwistle cuatro grandes tipos de baladas: históricas, procedentes de la tradición literaria (épicas, saga-románticas, pastorales, clásicas, religiosas), de aventuras y mitológicas.
} 
cuando entra en juego la teoría de las formas simples de Jolles. Sus formas simples son géneros que tienen un papel clave en esa transición de la oralidad a la escritura, aunque el propio Jolles no explotara esa potencialidad. La línea de estudio de las formas simples ha tenido una continuidad más allá de la obra de Jolles. Walter A. Koch (1994) ha publicado un manual de gran interés, en el que aparecen cuarenta y cinco formas simples. Son cinco veces más que las que propusiera Jolles. Y, sin embargo, algunas tan centrales como el caso no figuran en la recopilación de Koch. Koch parece haber pensado en los folcloristas a la hora de desplegar sus categorías. Un planteamiento que se enfrente a los géneros del discurso que aparecen bajo los temas del romancero puede ser útil para reconocer el $\mathrm{ADN}$ de este género $\mathrm{y}$, en general, de la poesía oral. Tal planteamiento nos llevaría a clarificar la noción del carácter épico-lírico de baladas y romances, que tanto debate ha producido y que sigue siendo tan difuso, a pesar de que la escuela española ha visto en ella la principal certeza del espíritu del romancero.

\section{FORMAS SIMPLES}

A continuación expondremos las principales formas simples, ejemplificándolas con sus correspondientes romances.

\section{El caso}

El caso es una forma simple muy prolífica en la tradición y que mantiene su presencia en géneros culturales modernos, tanto literarios, musicales o espectaculares (el cine, el teatro). Son también muy importantes los casos judiciales y clínicos, esto es, la casuística científica. En cuanto género de la enunciación presenta una transgresión del orden social o suceso extraordinario que precisa un juicio. Tiende a relatar con detallismo los pormenores del suceso, los factores agravantes o eximentes, los aspectos técnicos, etc. En su forma completa termina con la resolución condenatoria o absolutoria. También suele contener diálogos y una enunciación narrativa elemental, que se establece como una sucesión de acontecimientos. Suele decirse que el caso es el relato de un suceso inusitado. Jolles aporta un ejemplo muy difundido en las culturas europeas: la querella sobre el tonel centenario. Se ha descubierto un tonel que contiene un vino centenario. Dos expertos lo degustan. Uno encuentra un ligero sabor metálico. El otro, en cambio, percibe cierto sabor a cuero. Vaciado el tonel se encuentra una llave con trozo de cuero atado a ella. Esta definición de suceso inusitado la empleó Goethe para referirse a la novela corta. Pero nuestra con- 
cepción de estas palabras es mucho más amplia que el concepto de novela, al que abarca parcialmente, pues no toda novela expone un caso. Ese relato de un suceso inusitado tiene una prehistoria: es, en primer lugar, un género tradicional (o folclórico). Despliega después un rico abanico de posibilidades en las disciplinas y las artes históricas. Y adquiere hoy una nueva trascendencia. El enorme papel cultural que ha desempeñado y está llamado a desempeñar el caso lo convierte hoy en un género fundamental y decisivo en el complejo proceso de construcción de la humanidad. Precisamente por su ubicuidad, trascendencia y proteísmo ha pasado prácticamente desapercibido para los estudiosos, con la excepción de Jolles. La investigación ha preferido centrarse en géneros cuyo papel puede ser determinado eficazmente por medios empíricos, aunque no se renuncie a otras formas de conceptualización (la teoría) ${ }^{4}$.

En Occidente, Jolles aprecia una dinámica peculiar del caso. Esta dinámica requiere trazar la historia del caso y de las migraciones y modificaciones de cada caso. Jolles renuncia a esa tarea, pero apunta una serie de problemas que se orientan en esa dirección. Se trata de una enumeración de dominios con presencia del caso: la lógica, el amor cortés, la teología moral y, en general, cualquier disciplina que permita y exija la evaluación. Estos dominios ofrecen un lenguaje común, el lenguaje de la casuística, que permite evaluar según normas (1972: 154). Jolles aprecia otro rasgo del caso: la recompensa. La recompensa es al caso lo que la reliquia es a la leyenda y el símbolo, al mito.

En el romancero, el caso puede comportar una dimensión histórica, lo que lo convierte en una anécdota. Pero esa dimensión anecdótica puede perderse y se pierde en la tradición moderna en numerosas ocasiones, porque no es lo esencial de la forma simple. Lo esencial es una enseñanza de cómo puede

\footnotetext{
${ }^{4}$ Jolles se fijó en la importancia de la casuística en el derecho y en la moral. Por esta razón tomó el nombre de caso para esta forma simple. Según Jolles (1972: 143), el caso ha de ser diferenciado del ejemplo y de la muestra porque se funda en "una disposición mental que se representa el universo como un objeto que se puede evaluar y juzgar según normas". El caso judicial o moral constituye la forma simple actualizada. Y a esta le corresponde una forma sabia: la novela corta (Jolles utiliza la forma Novelle, que no tiene equivalente en español). Para mostrar esto, Jolles ofrece un listado de obras que contienen casos: los Gesta Romanorum, las Mil y una noches, el Decamerón y el hindú Kathasantsapara o El océano de los relatos, del que ofrece y analiza un ejemplo que tiene más de acertijo que de caso. Esto responde al criterio de Jolles (1972: 150) que ve el caso vinculado a la pregunta, que él percibe como distinta de la que se puede encontrar en el mito y en la adivinanza, pues contiene una interrogación sobre la norma misma. De aquí Jolles (1972: 151) extrae una conclusión: el caso es un género que deja de ser tal "cuando una decisión positiva neutraliza el deber de decidir". Esto es lo que ocurre cuando el caso avanza hacia su forma sabia correspondiente, la novela. En la Novelle el caso deja de ser caso, pero "la desaparición de un caso entraña la aparición de otro", lo que en El océano de los relatos permite dar paso mediante una fórmula al siguiente caso mediante la fórmula: "el cadáver se encuentra colgado de la higuera”. El conjunto del Océano sólo puede terminar cuando un caso no se resuelve y no llega a ser una verdadera Novelle.
} 
transgredirse el imperio de la ley tradicional. En cuanto anécdota, se presta a un proceso de selección. Desaparecen los elementos de historia personal (otra forma simple tradicional que encontraremos esporádicamente en el romancero), para centrarse en el suceso y el proceso a que da lugar. La tradición moderna puede operar en dos direcciones: ampliar el detallismo del caso novelizándolo y, al contrario, perdiendo detalles concretos. Quizá el romance-caso modélico sea "La jura de Santa Gadea" (V, 23 y VI, 16). También el romance de "La dama pleiteada", de la tradición vulgar según de la Campa (V, 43 y VI, 29; y $\mathrm{S}, 87$ ) responde a este modelo. En "La jura de Santa Gadea" podemos apreciar tres de los rasgos más característicos del caso. En primer lugar, que hay un juicio, convertido en jura. La afrenta al rey Alfonso consiste precisamente en que la toma del juramento significa un juicio a quien no se puede juzgar. En segundo lugar, es característico de los casos el detallismo de la descripción de la situación —a veces, del crimen-. En "La jura..." se aprecia en la mención de los símbolos jurídicos: "sobre un cerrojo de hierro y una ballesta de palo". Y, por último, no falta la recompensa, que aquí es un castigo: el destierro. Esta inversión de la recompensa en castigo es un motivo épico. El romance de "La dama pleiteada" contiene, en su versión vulgar, las tres características mencionadas: juicio entre el amante y el marido, detallismo en las alusiones al tiempo y aspectos del episodio y la recompensa. La dama se libera del matrimonio no deseado con el rico mercader y puede vivir con el amante Don Juan: "Y al fin vinieron contentos los que tanto se querían". Pero, además de la estructura del caso conlleva la estructura del milagro de la Virgen, porque la Virgen se apiada del dolor de don Juan y resucita a la difunta doña Ángela. Salazar recoge dos series de romances de casos y sucesos (S 36-49 y 63-72). Algunos romances de estas series, junto a otros de la serie de los moriscos, atestiguan la presencia, tal vez creciente, del caso en la tradición moderna.

\section{La historia personal}

Un paso más allá del caso nos lleva a la historia personal. Historias personales son "Gerineldo" (V, 1 y VI, 1), "Marquillos" (V, 2 y VI, 2), "El caballero burlado" (V, 4 y VI, 3), "Don Fadrique, el maestre de Santiago" (V, 29 y VI, 22), "El conde Claros" (V, 32 y VI, 25) y "La Cava” (V, 37). Jolles no recoge esta categoría, que, sin embargo, es hoy comúnmente aceptada en los estudios de folclore. La categoría más próxima en el elenco de Jolles es lo que denomina Memorabile (en la traducción francesa le mémorable). Tanto el término como su concepto los deriva de los apomnémoneumata de Sócrates, los Recuerdos de Sócrates de Jenofonte. Y a este género vincula los recuerdos de Jesús de los evangelistas. Para Jolles, lo memorable es la forma en la que todo 
deviene concreto. Los hechos aislados se ensartan en una relación cargada de sentido y todo elemento toma sentido en esa relación y en su relatividad (Jolles, 1972: 167). Aunque está definición resulta parcial vista desde la perspectiva de lo que vamos a llamar historias personales, hay que reconocer que esas historias personales se asientan sobre un hecho trascendente - un crimen, una ofensa o la ruptura del orden social, como la fuga de dos amantes o su matrimonio no aceptado por la autoridad competente-.

La historia personal admite un tratamiento tragicómico, caracterizado por el final feliz. Probablemente el final feliz sea una característica de la pervivencia de la más antigua tradición, pues en el cuento tradicional vemos cómo el final feliz es obligado. Así sucede con las versiones de la tradición antigua de los romances mencionados. En cambio, si observamos las versiones de la tradición moderna de esos romances veremos que el final ha sufrido cambios, bien sea porque desaparece o se contradice mediante burla el elemento feliz (esto ocurre en la versión moderna de "Gerineldo" citada, en la que Gerineldo rechaza el casamiento con una mujer deshonrada), porque el final recibe una carga dramática suplementaria (como puede apreciarse en la versión moderna de "Marquillos" o porque desaparece el motivo del castigo del perverso en la versión moderna de "Don Fadrique"). En la tradición moderna son más habituales los tratamientos dramáticos e, incluso, tremendistas: crímenes y castigos capitales. Ha llamado la atención el hecho de que el romance de "Don Fadrique" esté relatado en primera persona, incluso cuando la cabeza de don Fadrique ha sido separada de su cuerpo y responde a doña María de Padilla. Este aspecto enunciativo tiene su explicación en que se trata de una historia personal y esta forma admite en ciertas condiciones la narración personal (esto es, en primera persona).

La historia personal es quizá la forma más frecuente del romancero vulgar y moderno. "La monja por fuerza" ( $\mathrm{S}, 34)$ nos sirve de ejemplo. Una joven es internada por la fuerza en un convento. Desde lo alto de un convento ve venir a un caballero y le pide que la rescate. El caballero se niega y ella se suicida. Son frecuentes las historias con nombre y apellidos.

\section{La anécdota y la materia histórica}

Uno de los ámbitos convencionales del romancero es el de la materia histórica, que se diferencia de la materia de origen épico en que no está filtrada por géneros orales. El hecho de que la anécdota acceda a la tradición sin un tratamiento épico o legendario hace que no se contamine de elementos fabulosos. $\mathrm{Su}$ verosimilitud le confiere un aura de realismo. Jolles no reconoce la anécdota como tal, pero el capítulo que dedica a lo Memorabile, los recuerdos, plantea el mismo problema del material histórico y bien podría decirse que la anécdota 
para él estaría comprendida en esa categoría de lo memorable, en cuanto testimonio de un suceso o escena del que se da testimonio. El romancero ofrece, en este sentido, una dimensión que ilustra la transición de la cultura tradicional primitiva a la cultura histórica, porque en su origen el romancero se fija en las gestas (por su origen épico) y, después, lo vemos fijarse en anécdotas, que son sucesos históricos. Gestas y anécdotas son dos formas diferentes de comprender el material histórico dentro de la tradición — la tradición épica y la tradición moderna-.

La materia propiamente histórica romanceril se presenta como anécdotas. La anécdota admite tratamientos en prosa (la literatura sabia de la Antigüedad: Frontón, Ateneo, Aulo Gelio, Macrobio... y todo el universo de los facta et dicta) y en verso. El romance se presta a la difusión de la anécdota en verso. A tal forma simple corresponden los romances "La muerte de Alejandro" (V, 12 y VI, 9), "Fernán González se niega a ir a las Cortes" (V, 16), "La muerte del rey don Fernando" (V, 20), "Quejas de Urraca”, que combina anécdota y lamentación $(\mathrm{V}, 21)$, y "La muerte del príncipe don Juan" (V, 30), que combina anécdota y consolación. Estas anécdotas suelen ser históricas pero también pueden ser mítico-religiosas, como el romance nuevo "El niño perdido y hallado en el templo".

La anécdota combina hechos y dichos. La palabra es muy importante y queda realzada por la situación extraordinaria (la presencia de la muerte o de algún momento decisivo para la vida del personaje, factores que aportan dramatismo). Ya hemos mencionado romances de actos de habla: quejas, testamentos, declaraciones... Estas formas están relacionadas con la forma simple que Jolles llama Spruch, es decir, proverbio, refrán o dicho.

La lectura más generalizada ve estos romances como noticiosos. Sin embargo, la tradición excluye la novedad. Más acertado sería pensar que la dimensión dramática transforma la noticia en anécdota y que esto legitima la constitución del romance. Se trata de la forma simple romanceril más didáctica. Esto supone que no hay una trama sino la exposición de un estado de conciencia. La historia ya es conocida por los oyentes y lo esencial pasa a ser la lección que contiene la anécdota.

La anécdota histórica apenas tiene presencia en el Romancero vulgar y nuevo, a juzgar por la recopilación de Flor Salazar. Su clasificación solo presenta tres romances: "Testamento de Felipe II", "Testamento de Felipe III" y "El conde y la condesa de Aliste" (S 29, 30 y 31). El primero y el tercero son dos casos y la dimensión histórica es superficial. En el segundo, no está claro lo que pueda ser, pero tampoco tiene una dimensión histórico-anecdótica. Quizá pueda deducirse que la forma anecdótica solo se conserva en la tradición antigua y se difumina en la tradición moderna, tal vez porque la anécdota histórica encuentra otras posibilidades de expresión popular. O, quizás, porque la cultura 
popular moderna no se interesa por la materia histórica, que es patrimonio de la cultura elevada.

\section{La lamentación}

La lamentación es un género bien conocido en la poesía tradicional. Tampoco fue considerada como forma simple por Jolles. Sin embargo, tiene un amplio recorrido en el panorama de la literatura universal. El ejemplo que ha servido de modelo son las "Lamentaciones" de Jeremías. Los griegos llaman a este género thrénos. Es un género funerario en su origen. Pero también se presta a un tratamiento elegíaco y anecdótico-histórico, que es el que prevalece en el romancero. Es frecuente la aparición de la primera persona y se presta a una fragmentación trovadoresca (cortesana). Son lamentaciones "El prisionero" (V, 6 y VI, 5), "Fontefrida" (V, 6 y VI, 5) "El infante cautivo" (V, 8 y VI, 6), "Don Rodrigo abandona la batalla" (V, 14 y VI, 11), "El entierro de Fernando Arias" (V, 22 y VI, 15, éste novelizado), "El amante despreciado/Maldita seas ventura", que se funda en el motivo de "la belle dame sans merci" (V, 33), "El llanto del pastor enamorado" (V, 34 y VI, 26, en éste la lamentación se desplaza a las tres mujeres), "Gritando va el caballero", lamentación por la amada muerta antes de disfrutar del amor (V, 35), "Sale la estrella de Venus [Lope]" $(\mathrm{V}, 38)$ y "De las cañadas de pino" (V, 40). En esta breve lista se observa el desplazamiento de esta forma simple elegiaca hacia el ámbito pastoril. La estética pastoril (églogas, novela y comedia) lleva a su máximo desarrollo el género de la lamentación (los cinco últimos romances mencionados son pastoriles o comparten esa estética). Este carácter pastoril contiene dos aspectos significativos: la transición de la poesía popular a una forma mixta popular-culta, que Lope y los grandes poetas de los siglos XVI y XVII cultivan; y la formación de una estética mixta: tragicómica o joco-seria. La figura del pastor representa, de forma sublimada, el mundo de lo bajo, lo cómico, y la "belle dame sans merci”, la dama que se niega al amor, el mundo elevado. Este género no suele precisar rasgos circunstanciales, a diferencia del caso, lo que facilita su sincretismo (entendido habitualmente como fragmentarismo) y tampoco suele recurrir al diálogo (suelen ser monólogos). Todo ello dificulta su novelización.

\section{La consolación}

La consolación es un género que admite un tratamiento poético y prosaico. Tampoco es reconocida como forma simple por Jolles. Se trata de un género que busca indagar en la naturaleza humana para alcanzar un estadio de conciencia 
superior. Ese estadio debe permitir al sujeto de la consolación alcanzar una superación moral de un estadio de lamentación. Presenta una gama que puede ir del testimonio personal a una fusión con otros géneros fronterizos (el caso, la lamentación, la fabulación, la novelización). Por supuesto, también admite un tratamiento intelectual, que suele ser patrimonio de la prosa culta (los estoicos, Boecio). La presencia de este género en el romancero no es tan importante como la de las otras formas simples que analizamos. Con todo, el romance "El sueño de doña Alda" (V, 25 y VI, 28) es una consolación. El suceso trágico y el presagio (la muerte de Roldán) se ven compensados por la consolación en el amor más poderoso que la muerte, motivo que pervive en la poesía culta humanista. Una forma distinta de consolación la encontramos en el romance de "La muerte del príncipe don Juan" (V, 30). Con este romance sucede algo parecido al anterior. Su núcleo es una anécdota histórica (la muerte del infante don Juan, único hijo varón de los Reyes Católicos). La consolación es sólo un momento del poema. El infante, en el lecho de muerte, consuela a su padre ${ }^{5}$. Estos datos sugieren que la forma consolación no participa del espíritu del romancero. Un tercer ejemplo, "El niño perdido y hallado en el templo" de Alonso de Ledesma (V, 42), versión a lo divino del romance de Lope "La diosa a quien sacrifica" (V, 39), combina lamentación y consolación. Igualmente sucede con "Quejas de la Magdalena" de López de Úbeda (V, 41), que combina las lamentaciones de la Magdalena con la consolación de Cristo. Es comprensible esta asociación de las dos formas, que son los dos polos de la actitud frente a la muerte y la desdicha.

Estos romances apuntan a que la consolación sólo cabe ante la muerte y la promesa de una vida superior (ya sea simbólica, como en el romance de doña Alda, o religiosa). Es, pues, la consolación una forma simple que roza el universo del romancero o que no ha gozado de las preferencias de los compiladores.

\footnotetext{
5 José Manuel Pedrosa (2006) ha recogido la siguiente versión del romance de "La muerte del príncipe don Juan" en Foldada (Palencia), recitado por la señora Cesárea Ruiz el día 6 de julio de 1989. Lo cito a continuación para observar que, pese a los cambios operados respecto al romance viejo por la tradición moderna, permanece inalterable la forma estética: lamentación + consolación:

¿Qué se cuenta por Asturias, qué se cuenta por Granada, / qué se cuenta por Asturias? Que don Juan está en la cama. / Siete médicos le asisten de los mejores de España; / unos le curan con vino y otros le curan con agua, / y otros por no darle pena que lo que tiene no es nada. / Ya faltaba de venir el director de la sala, / y éste le ha tomado el pulso y le ha dicho como se halla. / Tres horas le quedan libres de descanso en su casa, / hora y media que disponga de las cosas de su alma, / la otra hora y media que queda, de la gente de su casa. / Y estando en estas razones, su esposa entraba en la sala: / - ¿Dónde has estao, esposa mía, esposa mía del alma? / -Rezando a Santo Domingo que te saque de la cama. / -Muy pronto me sacará, el lunes por la mañana, / con los pies amarillentos y la cara amoratada. / Su esposa, de que lo oyó, cayó al suelo desmayada, / y viendo que no volvía, ni con vino ni con agua, / trataron de abrirla el vientre y un lindo niño la sacan, / que es más hermoso que el sol y que es más lindo que el agua. / Y se le dan a su padre, que la bendición lo echaba: / -Si te crías pa este mundo, serás primer rey de España, / y si te crías para el otro, en la gloria Dios te haga.
} 


\section{La broma y el engaño}

Si la anécdota es la forma más didáctica del romancero la broma y el engaño son las formas más cómicas. Esta forma simple sí que es reconocida por Jolles (1972: 197-207), que la denomina Witz —en la versión francesa trait d'esprit-. Witz, según Jolles (1972: 198), es la forma que desnuda las cosas, que deshace los nudos. Para cumplir esa tarea de desnudamiento, debe darse una condición: la insuficiencia. Y la consecuencia de la insuficiencia es la burla (Jolles, 1972: 202). El romancero conoce formas tragicómicas y cómicas, basadas en la burla. Éstas se corresponden con géneros cómicos populares que se dan más allá del romancero. Una de estas formas es la burla-engaño. La burla suele fundarse en la figura del trickster o burlador y su forma más conseguida es la del burlador burlado ${ }^{6}$. A esta línea pertenecen los romances "Galiarda" (V, 3, aunque aquí se trata más bien de un doble burlador), "El caballero burlado" (V, 4 y VI, 3), "La dama y el pastor" (V, 5 y VI, 4), "Las señas del esposo" (V, 11 y VI, 8 a y b) y "El moro que reta a Valencia" (V, 24 y VI, 17) que explota cómicamente el pasaje del Cantar del Cid en el que el rey Búcar huye del Cid. Una de las variantes del romance burlesco es la pastorela. Pero la burla pastoril suele preferir formas más apropiadas para la comicidad (serranillas, farsas...).

Conviene que nos detengamos muy brevemente en el romance "Fontefrida" $(\mathrm{V}, 7)$. Este romance está vinculado a esta forma burlesca, pues el ruiseñor es un trickster ("malo, falso, engañador"). En la forma cancioneril en la que nos ha llegado el romance, más que un burlador burlado es un burlador rechazado. Hay además un segundo aspecto de este poema: se trata de un apólogo. El apólogo es un cuento popular de animales a los que se les atribuye rasgos humanos (sentimientos, palabras, valores). El apólogo es una de las formas cómicas populares más antigua y fecunda. Su presencia en el romancero es escasa, pues el romancero se nos ofrece como una etapa relativamente tardía de la tradición, la tradición épico-lírica.

Salazar reúne tres series cómicas: romances de guapos ("El guapo Luis Ortiz", "Bernardo del Montijo" y "El bravo Fulgencio Flórez de Aranda"; S 107-109), de galanteos y burlas amorosas ("La rueda de la fortuna", "La dama y el mozo bizarro", "María confía su deshonra a Juana", "El indiano burlado", "Las mozuelas de la alameda" y "El capitán burlado"; S 110-115) y romances jocosos y burlescos ("La adúltera con el cebollero", "El fraile y el burro de la hortelana", "Amante apaleado", "Chasco que le dio una vieja a un mancebo", "Pregunté si había cena", "De los dos, de los dos, de los dos", "La mujer del

${ }^{6}$ La figura del trickster o burlador ha dado lugar a una amplia bibliografía que abarca desde el ensayo que le dedicara Carl G. Jung —Acerca de la psicología de la figura del trickster (1954) - a otras más recientes debidas a folcloristas o teóricos de la risa (Beltrán, 2011: 35-41). 
calderero", "Un barbero fue a moler", "El milagro de san Bartolo", "Testamento del pastor" y "El testamento del burro"; S 116-126). Estas series atestiguan una relación muy estrecha con los cuentos populares de carácter costumbrista. A estas series cabría añadir los testamentos burlescos. Según Maxime Chevalier (1992: 78) poseemos una considerable cantidad de versiones manuscritas: la del romancero de la Biblioteca Branccaciana, las conservadas en bibliotecas madrileñas, la de un cancionero de la Biblioteca de la Accademia dei Lincei y la de un documento del archivo de Pamplona, fechada en 1619.

\section{Sueños y milagros}

Estas formas dan lugar a los romances herméticos. Jolles no contempla sueños y milagros como formas simples, pero sí la adivinanza (Rätsel, traducida al francés como devinette). La adivinanza y el enigma son formas herméticas. El hermetismo es una estética de origen tradicional que suele aparecer en los romances en forma de episodios. Esta estética se ocupa de los momentos decisivos de una vida en clave dramática y mágica, normalmente anticipatoria. Estos momentos decisivos constituyen el destino y deciden la salvación o la condena de las figuras que los sustentan. Una dimensión sobrenatural caracteriza esos momentos. Los sueños, presagios y anticipaciones son los motivos más frecuentes en el romancero y en la épica. Un romance fundado en un sueño es el del "Sueño de doña Alda" (V, 25 y VI, 18). El que tenga tradición moderna es un indicio de que el romancero no excluye esta estética. La abundancia de presagios y anticipaciones, heredada de la épica, constituye otro indicio. "Melisenda insomne" $(\mathrm{V}, 28)$ también participa de esta forma onírica, aunque sólo sea por negación.

Otra dimensión hermética son los misterios, metamorfosis y milagros. Los milagros son bien conocidos en la literatura castellana por su presencia en el mester de clerecía. Pero esa es solo la vertiente culta — por su origen latinode un universo con gran arraigo popular. Suponen la intervención de las figuras divinas o semidivinas - los santos - en asuntos mundanos. Esa convivencia de dioses y mortales solo es posible en un estadio de la tradición épica y en las primeras etapas de la tradición épico-lírica, aunque, como vamos a ver, sobrevive en el Romancero moderno ${ }^{7}$. Los milagros de santos suelen serlo post mortem, como manifestación de la superioridad de la vida sobre la muerte gracias a la fe. Los misterios suelen estar vinculados a los oficios religiosos, pero además

${ }^{7}$ La presencia de los dioses griegos en la Iliada es posible por la credulidad que requiere la tradición épica. Esa misma credulidad es la que podemos apreciar en la tradición de milagros de la Virgen. En la tradición moderna el milagro se retrae a las capas más profundas del imaginario de sectores populares ingenuos. 
de la teatralización del culto están presentes en otros géneros tradicionales, entre ellos el romancero. La metamorfosis se funde con la identidad en la imagen tradicional-folclórica del ser humano (Bajtín, 1989: 265). La metamorfosis aparece en los misterios del culto cristiano en forma de elementos rudimentarios mágicos. También tuvo presencia en el ritual popular medieval y, de ahí, pasó a los géneros literarios. Se caracteriza la metamorfosis por una representación mágica, esto es, a saltos, de la evolución y de la vida. Tanto en los misterios como en las metamorfosis la vida entera entra a formar parte del relato, aunque sea en la forma mágica que concentra esa vida en los momentos reveladores. Veamos algunas muestras de la presencia de estas categorías y de su interrelación en el romancero.

El romance "Lanzarote y el ciervo de pie blanco" (V, 13 y VI, 10) contiene misterio, metamorfosis, misión imposible y una maldición final. Pero la presencia más habitual del hermetismo en los romances no es la de constituir un núcleo mágico o mistérico sino la de aportar elementos herméticos —maldiciones, presagios, pronósticos...- a otra forma simple, por ejemplo, al caso. Así ocurre en el "Romance del rey Fernando IV, el emplazado", en el que los hermanos Carvajal, al ser ajusticiados injustamente, emplazan al rey Fernando a morir en un mes. Flor Salazar aporta milagros en el romancero vulgar y nuevo: "Madre que maldice a su hijo" (S 204 y 205), "El contrato del diablo" (S 206), "La toca de la Virgen y el alma pecadora" (S 210) o "La monja seducida por el diablo" (S 214). Estos últimos pertenecen a la serie de milagros de la Virgen. Los romances recogidos por Salazar entre el 170 y el 192 son "de apariciones y milagros". También son herméticos los numerosos romances vulgares o modernos basados en la figura del diablo. El hermetismo entiende el universo como el escenario de la lucha eterna entre el bien y el mal. Figura clave de la encarnación de esa lucha es el diablo. Y su opuesto suele ser Cristo, que también ha dado lugar a una amplia serie de romances modernos.

\section{La fábula y la leyenda ${ }^{8}$}

Otra forma simple del romancero es la fabulística. Esta forma está emparentada con el hermetismo, aunque su simbolismo suele ser más didáctico que hermético. Bien podría definirse ese simbolismo como un didactismo con elementos herméticos o religiosos. En la forma romance caben varios tipos de

\footnotetext{
${ }^{8}$ Los seguidores de Jolles han especulado con que el maestro considerara la posibilidad de una décima forma simple que sería la fábula, pues entendían que entre la leyenda y el cuento cabía la fábula. Pero Jolles reduce la leyenda a la leyenda cristiana de mártires y santos. Véase el prólogo del editor francés al libro de Jolles (1972: 7-9).
} 
fábulas. El primer tipo, quizá el más interesante desde un punto de vista estético, es el del apólogo. Por apólogo suele entenderse una fábula de animales o, al menos, de figuras no humanas. Ya hemos mencionado el caso de "Fontefrida". Otra forma derivada del apólogo es la personalización de las ciudades, lo que ocurre en el romance "Abenamar". En este romance Granada, transfigurada en mujer, sostiene un diálogo con el rey don Juan, al parecer, siguiendo una tradición árabe. Una tercera forma es la fábula mítica, que aparece en el romancero nuevo: "La diosa a quien sacrifica" de Lope. Sin embargo, la fábula típica del romancero moderno es la evangélica (S 245-250). La forma leyenda permite a la tradición moderna incorporar y reelaborar la historia sagrada o historia mítica. Esto supone introducir en la tradición un material que procede de la lectura. Salazar llama a estos romances legendarios "beatos y edificantes". Son, en efecto, legendas piadosas, concebidas para la predicación y, por tanto, instrumentos similares al EXEMPLUM que se introduce en el sermón. Y los recoge en tres grupos: Romances de la Sagrada Familia (S 127-147), Romances de la predicación y muerte de Cristo (S 148-156) y Romances en que Cristo visita el mundo (S 157-169).

Si seguimos al pie de la letra la lección de Jolles el más genuino romancero legendario sería la tradición hagiográfica que se incorpora al romancero (Jolles: 27-28). Jolles entiende la leyenda como material de lectura (legenda) y menciona las Acta Martyrum o Acta Sanctorum como el núcleo duro del género. La hagiografía puede transitar por leyendas, protonovelas o baladas. Quizá la incorporación de la hagiografía al dominio de la balada sea un fenómeno tardío, limitado al romancero vulgar y moderno. En el tiempo del romancero viejo tenemos vidas de santos en cuaderna vía (las de Berceo). Salazar ofrece muestras de esta presencia en la tradición moderna: "El martirio de Santa Águeda", "San Alejo", "La esposa de San Alejo", "Santa Teresa niña y su hermano Rodrigo", "Santa Teresa niña quiere ser mártir", "El niño perdido de San Antonio" (S 245-250) y otros incluidos en diferentes series: "San Antonio y los dos hermanos" (S 236), "Milagro de la Virgen de la Estrella" (S 179)... Lorca, en su Romancero gitano, incluye su romance "El martirio de Santa Olalla".

\section{La protonovela}

Uno de los fenómenos más interesantes del romancero es la novelización de los romances, un fenómeno que participa en otro más amplio: la novelización de la tradición. Ciertos romances adoptan una forma próxima a la protonovela, un proceso mediante el cual diversos géneros orales y mixtos (orales posteriormente transcritos) se desgajan de su respectiva tradición nacional y, gracias a la traducción, se ofrecen al incipiente horizonte de la literatura universal en for- 
mato más o menos novelizado, pudiendo aparecer en otras lenguas y con otros propósitos (Beltrán, 2009). La debilidad de la tradición permite que ciertos relatos se emancipen o, al menos, se liberen de las determinaciones propias de la tradición en la que surgieron. La consecuencia de este proceso de liberación es el desarraigo de estos relatos $\mathrm{y}$, en tanto que desarraigados, se permiten traspasar las fronteras nacionales de la tradición (lo que puede dar lugar a fenómenos de traducción). En el romancero encontramos una larga serie de romances novelizados. Algunos provienen de la materia de Bretaña y son, por tanto, traducciones. Otros provienen de la materia castellana (Bernardo, Fernán González, los infantes de Lara...). El rasgo más acusado de estos romances novelizados es la acumulación de formas simples que presentan. No es casual. La protonovela es el producto de la mixtificación. Y ese fenómeno, la mixtificación, alcanza también al romancero.

Veamos algunos ejemplos. Quizá el caso más evidente de novelización sea el ciclo de romances de Durandarte. La personificación de la espada de Roldán, Durendal, da pie a la gestación de un caballero, Durandarte, que protagoniza una serie de romances. El romance "Espinelo" (V, 9 y VI, 7) es una historia personal que apunta a la protonovela. Pero esta historia personal va más allá de esta forma. Es el relato de un moribundo a su "amiga" Mataleona, lo que le aporta dramatismo. Espinelo comienza por relatar su linaje. Sigue con un caso. Este caso, a su vez, combina varios motivos del folclore europeo y universal: los partos dobles, la mujer falsamente acusada, el niño abandonado a su suerte en el mar y dentro de una cesta, la adopción por un soberano extranjero, la anagnórisis... Esta acumulación de motivos recuerda dos novelas medievales emparentadas: Pierre de Provence y la bella Maguelonne e Imberio y Margarona. La primera es una novela hoy perdida de un canónigo francés del siglo XII llamado Treviers y la segunda es una novela bizantina del siglo XV basada en la anterior. La conexión entre los tres relatos es evidente porque los tres siguen el modelo de la novela de aventuras de tipo griego. Además parece evidente la conexión entre los nombres de Mataleona, Maguelonne y Margarona. "Espinelo" es una novela de aventuras truncada, al menos en la versión mencionada, procedente de Rosas de romances (1573). No le faltan a este romance elementos cómicos (la burla del nombre).

También tiene una forma novelística embrionaria el romance "Lanzarote y el ciervo de pie blanco", que ya hemos mencionado. Su carácter hermético lo vincula a la tradición de novelas simbolistas y herméticas medievales (desde el Pseudocalístenes o Véltandro y Crisantza a Gawain y el Caballero Verde o Pedro el Labrador). Otra característica de las protonovelas romanceadas es su eclecticismo. Los romances "Bernardo se entrevista con el rey" (V, 15 y VI, 12) y "Fernán González se niega a ir a las cortes" $(\mathrm{V}, 16)$ son fragmentos protonovelísticos que funden además casos y bromas. Hay también en ellos un ele- 
mento de burlador burlado (la trampa evitada, "aquestas burlas"). No es necesario subrayar la importancia de la serie de romances sobre los infantes de Lara (V, 17-19 y VI, 13), auténtico best seller medieval y posterior. Joan de Timoneda compondría una versión novelizada $(\mathrm{V}, 36)$. Esta serie se basa en un caso, pero acoge otros elementos que le prestan su enorme atractivo.

Ocurre también que ciertos romances funden otros romances o relatos. Un ejemplo es "Las quejas de doña Urraca" (VI, 14), romance de tradición moderna que integra los romances de los testamentos de Felipe III y Felipe II y las quejas de Doña Urraca a su padre moribundo. La forma testamento (los consejos de un moribundo) está aquí unificada mediante la figura de Felipe III.

El romance de "Moriana y Galván" combina caso, historia personal, sueño, amor mortal y otros vestigios épicos (V, 27 y VI, 20). "Melisenda insomne" (V, 28 y VI, 21) acumula también diversas formas y motivos, como ya hemos señalado. "El Conde Claros" es un caso-novela. Su detallismo, la complejidad de la peripecia y el final feliz transcienden el caso y lo convierten en una novela versificada. Por último, la serie de "La muerte del príncipe don Juan" noveliza una noticia (o, mejor, una anécdota) y contiene la lamentación del rey y la consolación a su padre del moribundo. Esta combinación de lamentación y consolación es, por sí sola, un principio de novelización.

En el romancero vulgar y nuevo la novelización se convierte en un fenómeno generalizado que aleja el romance de la estética tradicional. Los estudiosos han discriminado estos romances al entenderlos como producto de la degeneración de la tradición. Flor Salazar ha estudiado los romances "La difunta pleiteada", "Los privilegios del labrador" y "La fraticida por amor", que presentan versiones al estilo tradicional y versiones protonovelísticas (1999: XXXVII-LXI).

\section{EL CARÁCTER ÉPICO-LÍRICO}

El objeto de estos apuntes es aproximarnos al ADN del romancero, como hemos dicho más arriba. La crítica, en especial Diego Catalán (1997-1998), ha clamado por la autonomía del romancero respecto a otros géneros culturales. Sin embargo, cualquier lector puede apreciar que muchos motivos, temas y formas romanceriles son comunes a otros géneros (a la epopeya, a la lírica popular, al cuento folclórico, a la canción tradicional...). Este fenómeno de vinculación se debe a que, bajo la piel del género cultural, laten otros géneros más longevos y fecundos, aunque hoy casi invisibles, que son lo que venimos llamando formas simples, en honor a André Jolles. También la epopeya, la canción tradicional, el cuento popular y todos los grandes géneros contienen sus formas simples. Comprender estas formas simples nos permite conocer el alma de estos géneros. Es evidente que los géneros culturales presentan un abanico 
limitado de formas simples. En el caso del romancero hemos visto que algunas parecen primordiales: la historia personal, la lamentación, la anécdota, la burla y la mixtificación o protonovela. Otras permanecen marginales o, al menos, en un segundo plano: el caso, la consolación, el testamento, el milagro, el sueño, la fábula... También son importantes porque muestran zonas de transición hacia otros géneros culturales. Ciertamente algunas de las categorías que proponemos para el romancero no son formas simples. El hermetismo agrupa a otras formas menores (el milagro, el misterio, la metamorfosis...). La protonovela significa el principio de la mixtificación y, por tanto, es algo más que una forma simple. Otras categorías manejadas — la lamentación, la consolación, el testamento, incluso la consolación - sí pueden ser tomadas por formas simples, porque no se pueden descomponer en otras menores, pero no fueron consideradas por Jolles. El filólogo alemán manejó un criterio, el de la simplicidad, útil pero muy discutible. Se funda en el desarrollo de la filología en el primer tercio del siglo XX. Hoy podemos ir un poco más lejos. El cultivo de las teorías de la oralidad que florecieron en la segunda mitad del siglo XX —-McLuhan, Havelock, Ong y otros - nos permiten un planteamiento superior. Las categorías procedentes de la oralidad que sirven para constituir géneros de transición -épico-líricos- a la escritura componen una serie que merece ser estudiada. Ese estudio arrojará luz sobre la naturaleza de los nuevos géneros transitorios e históricos. Y en ese escenario cobra excepcional importancia la balada.

Para extraer la lección que encierran estas formas simples deberíamos componer el mapa de estas formas simples en los géneros culturales de la transición de la oralidad a la escritura, esto es, en el romancero, en el teatro popular, en el cuento, en la novella, y en la poesía y la canción populares (cancionero). Esta tarea ha sido emprendida por pioneros como Peter Burke. En el capítulo "Las formas tradicionales" de su libro La cultura popular en la Europa moderna Burke (1991) comienza abordando el problema de la balada. La balada es un género europeo (quizá deberíamos decir universal). El romancero es la balada hispánica. Burke da cuenta de su diversidad versal y de capacidad diversificadora. La sitúa en el contexto de otros géneros tradicionales. Los resultados son todavía demasiado generales. Podemos concluir que la balada se comporta como otros géneros tradicionales, aunque puede que tenga sus propias características. Nada esencial parece desprenderse de la sabia exposición de Burke. Sin duda, el comparatismo es el camino, aunque haga falta algo más que documentación. Por otra parte, sus enseñanzas estaban ya explícitas en el magnífico libro de William James Entwistle European Balladry, publicado por primera vez en 1939.

Pero, aun antes de emprender esta tarea, podemos encontrar algunas enseñanzas respecto al romancero. La primera de esas enseñanzas es la versatilidad estética del romancero. Esa versatilidad va del dramatismo de la historia personal a la comicidad de la burla, pasando siempre por un didactismo tradicional. 
Así suele ser con algunos géneros de la tradición: los que se comprenden como épico-líricos. Estos son géneros que florecen en una época de transición de mundos tradicionales a mundos abiertos y dotados de una civilización emergente. Esta fase de transición es internacional, frente al universo heroico que queda atrás que tiene un carácter nacional infranqueable. Por lo que respecta a Europa la etapa de esplendor épico-lírica abarca los siglos XIII al XVI, aunque tiene después una continuidad de menor relieve en el seno de la tradición vulgar y moderna. Esta etapa épico-lírica no solo se caracteriza por la fusión de elementos heroicos y elementos cancioneriles, sino que es posible $-\mathrm{y}$ es una de sus señas de identidad - porque la distancia entre la cultura letrada y la cultura oral es mínima, y esa cercanía permite el trasvase de la oralidad a la escritura. Es el momento de la irrupción de la balada, de la aparición de formas teatrales no cultuales, de la recolección de escritos y leyendas de crónicas nacionales, de la novelización del cuento tradicional, de la protonovela y de las primeras formas novelísticas (la novela de aventuras, los ciclos provenientes de la cultura tradicional [el ciclo de la mujer falsamente acusada y el ciclo del hombre perseguido por la fortuna] y ciertos tipos de novela didáctica y humorística), de la aparición de las nuevas costumbres — que compiten con las costumbres tradicionales-, de la recopilación de formas literarias paremiológicas, de proliferación de relatos y leyendas idílicas (pastoriles), de la difusión de espectáculos cómico-festivos y de la aparición de una poesía musical, tanto popular como cortesana. El simbolismo épico-lírico es tragicómico. Aparecen las primeras traducciones, a partir de relatos escindidos de la tradición. Los valores de la tradición heroica han entrado en crisis y se tiende a representar el conflicto de esos valores.

En un segundo momento podemos indicar algunos apuntes respecto de dos problemas: la tradicionalidad y la evolución del romancero. Hemos visto que el abanico de las formas simples es más limitado en el romancero viejo. Y que nuevas formas simples parecen incorporarse en el romancero vulgar y moderno. La explicación a estos fenómenos está también en relación a las etapas de la tradición. El romancero y el cancionero populares tienen su momento de esplendor en la etapa épico-lírica de la tradición ${ }^{9}$. Sin embargo, baladas y canciones populares sobreviven a esa etapa y se adaptan a las condiciones de la tradi-

\footnotetext{
${ }^{9}$ Menéndez Pidal traza una línea divisoria en el Romancero antiguo entre un primer momento más épico en el que "los protagonistas de las aventuras épico-líricas eran el infante 'joven de alta nobleza', lo mismo que en la vieja epopeya castellana, y el escudero 'joven que espera ser armado caballero', protagonista también en los cantares de amigo galaico-portugueses del siglo XIII, y estos dos tipos arcaicos, que aún perviven en los romances del siglo XV, se transforman a comienzos del siglo XVI en el conde y el caballero, que son los dos tipos novelescos que actúan en el romancero posterior" (1953: XIV-XV). Y concluye que la poesía popular tiene "épocas evolutivas bien señaladas" (1953: XV).
} 
ción vulgar y moderna. No es este el momento de abordar cuáles son esas nuevas condiciones, pero al menos una es evidente: el peso de la tradición se suaviza. La autoría es bastante más libre en la tradición vulgar que en la tradición épico-lírica. En la tradición moderna ese peso es todavía más leve y permite la improvisación, el rasgo más llamativo de la tradición moderna. Quizás la relajación de las normas de la tradición sea la causa de la incorporación de nuevas formas simples al romancero vulgar y moderno. En determinadas condiciones, la necesidad doctrinal, por ejemplo, figuras y momentos evangélicos se incorporan como fábulas al romancero. Y, al contrario, la desaparición de ciertos aspectos culturales medievales es la causa de la desaparición de ciertas formas simples con el romancero viejo. La pérdida de lo que Menéndez Pidal llamó tradicionalismo se traduce en novelización. Ese proceso sigue los pasos del fenómeno que hemos llamado protonovela y que se caracteriza por el alejamiento y la autonomía respecto a la tradición y, también, por una tendencia al eclecticismo. Ese eclecticismo se refleja en la acumulación de formas simples. Cuando estas formas son poderosas basta una sola para articular el romance. Cuando parecen más débiles el recurso suele ser acumularlas. Quizá el tradicionalismo pueda definirse por la capacidad de las formas simples correspondientes de sostener el romance sin recurrir a soluciones eclécticas.

Y, por último, subrayaremos la importancia de superar la concepción habitual del género basada en el tema para pasar a una metodología basada en la forma estética. Los estudios literarios modernos suelen confiar en la dupla categorial temaestilo, que es comprendida como una dualidad natural, legitimada por la dualidad retórica res-verba. Esta idea común hoy ignora los esfuerzos humanistas — sobre todo, de la corriente aristotélica- y modernos por fundar la categoría de la forma estética o forma interior. Para los aristotélicos esa forma era la forma del contenido. Y una corriente moderna que tiene sus primeros pasos en los románticos de Jena (Friedrich Schlegel y Novalis) y que cuenta entre sus partidarios a Lukács, Benjamin, Heidegger, Bajtín o Ingarden y, entre nosotros, a Claudio Guillén, Antonio García Berrio e Isabel Paraíso ha sostenido — con diferentes concepcionesla idea de la forma interior o forma estética como clave del discurso literario y de la estética literaria. Esa forma interior no es una forma abstracta sino concreta e histórica. Ver el Romancero a la luz de esta categoría puede ayudar a dar un nuevo impulso a los estudios de este género.

\section{BIBLIOGRAFÍA}

Bajtín, Mijaíl M. (1989): Teoría y estética de la novela, Vicente Cazcarra y Helena S. Kriúkova (trad.), Madrid, Taurus.

Beltrán Almería, Luis (2008): "El caso: de la oralidad a la escritura", Revista de literaturas populares, 1, VIII, pp. 77-101. 
Beltrán Almería, Luis (2009): "Teoría de la protonovela", en Ignacio Arellano, Víctor García Ruiz y Carmen Saralegui (eds.), Ars bene docendi. Homenaje al Profesor Kurt Spang, Pamplona, EUNSA, pp. 101-110.

Beltrán Almería, Luis (2011): Anatomía de la risa, México, Ediciones sin nombre-CONACYTUniversidad de Sonora.

Burke, Peter (1991): La cultura popular en la Europa moderna, Antonio Feros (trad.), Madrid, Alianza Editorial.

Campa Gutiérrez, Mariano de la (1998): Antología de la épica y el romancero, Barcelona, Biblioteca Hermes-Clásicos Castellanos.

Catalán, Diego (1997-1998): Arte poética del romancero oral, 2 vols., Madrid, Siglo XXI de España.

Chevalier, Maxime (1992): Quevedo y su tiempo: la agudeza verbal, Barcelona, Crítica.

Entwistle, William James (1969): European Balladry, $3^{\mathrm{a}}$ ed., Oxford, Clarendon Press.

Jolles, André (1972): Formes simples, Antoine Marie Buguet (trad). Paris, Editions du Seuil.

Jung, Carl Gustav (2002): "Acerca de la psicología de la figura del trickster (1954)", en Obra completa. Volumen 9/I. 9, Madrid, Editorial Trotta.

Koch, Walter Albert (1994): Simple Forms. an encyclopaedia of simple text-types in lore and literature, Bochum, Universitätsverlag Dr. Norbert Brockmeyer.

Martínez Torner, Eduardo (1966): Lírica Hispánica. Relaciones entre lo popular y lo culto, Madrid, Castalia.

Menéndez Pidal, Ramón (1953): Romancero hispánico (hispano-portugués, americano y sefardí). Teoría e historia, 2 vols., Madrid, Espasa-Calpe.

Pedrosa, José Manuel (2006): "Tradición medieval y tradición moderna en el romancero de Palencia", Culturas populares. Revista electrónica, 2, mayo-agosto, 22 pp. <http://www.culturas populares.org/textos2/articulos/pedrosa.pdf>

Rodríguez Puértolas, Julio (1976): "El romancero, historia de una frustración", Literatura, historia, alienación, Barcelona, Lábor, pp. 105-146.

Salazar, Flor (1999): El Romancero vulgar y nuevo, Madrid, Fundación Menéndez Pidal/ Seminario Menéndez Pidal/ Universidad Complutense de Madrid.

Fecha de recepción: 2 de septiembre de 2013

Fecha de aceptación: 27 de marzo de 2014 